\title{
Trauma; frequency of missed intra-abdominal injuries in Al- Sulaimaniyah Teaching Hospital/ Emergency Department
}

\author{
Hiwa O. Ahmed*, Salam Nizam Aldeen Shams Aldeen** \\ * Department of Surgery, Medical College, University of Al-Sulaimaneyah, Al-Sulaimaneyah City; \\ ** General Surgeon, Sulaimaniyah Teaching Hospital.
}

(Ann. Coll. Med. Mosul 2012; 38 (1): 15-19).

Received: $16^{\text {th }}$ Jun. 2010; Accepted: $12^{\text {th }}$ Jan. 2011.

\begin{abstract}
Background: The most common reason for injuries to be missed is altered level of consciousness due to head injury or alcohol. Other reasons include severity of injury and instability requiring immediate operation, lack of symptoms at admission, technical problems, and low index of suspicion by the examiner. Missed injuries can occur at any stage of the management of patients with major trauma. Any delay in providing the necessary treatment may lead to increased morbidity and mortality.
\end{abstract}

Objective: To find the frequency of missed intra-abdominal injuries and their mortality, to raise suspicion of potential missed injuries in order to avoid these preventable deaths.

Methods: A retrospective study including 2978 patients with abdominal injuries out of 13201 traumatized patients in 2006. Records were reviewed for demographics, injury characteristics, and associated injuries, missed injuries, need and indications of reoperation, morbidity and mortality.

Results: The study included 2978 trauma victims; 2195 males and 783 females, with a male to female ratio of about 4:1.Thier age ranged from 2- 87 years, median age 39.5 and peak age of trauma was 31 years. From 2978 patients with abdominal injuries, there were 28 deaths (1.06\%), and four missed injuries (0.134\%).

Conclusion: A careful history taking, precise and repeated clinical examinations, complete diagnostic procedures, complete surgical explorations, and proper timing of reoperation are necessary for patients with blunt abdominal injuries, which are cornerstones in improving the quality of trauma care.

Keywords: Trauma patient, missed injuries, missed abdominal injuries, small intestinal injuries, and preventable death.

الخلاصة

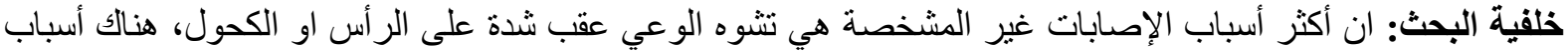

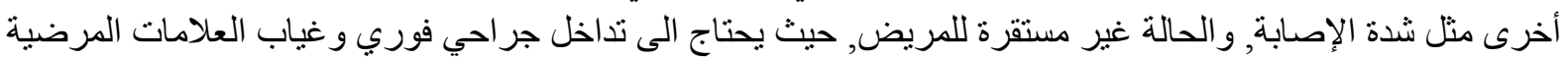

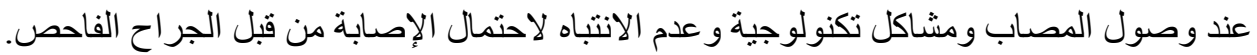

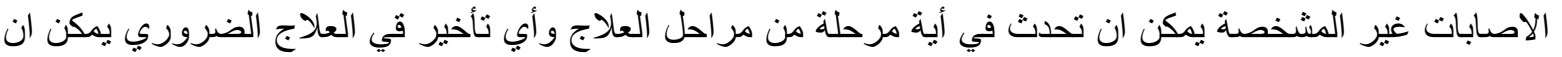
يؤدي الى المضاعفات أو الوفير الوفاة. هدف البحث: بيان مدى شيوع حالات إصابات البطن غير المشخصة واحتمال الوفاة كنتيجة, ولرفع الوعي حول احتمال

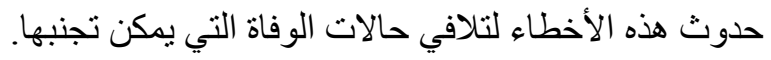

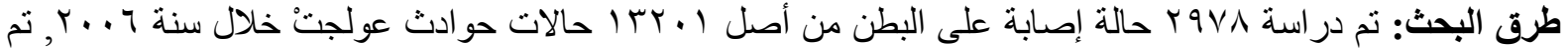

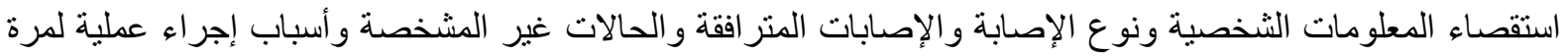
ثانية و المضاعفات وحالات الوفاة. 


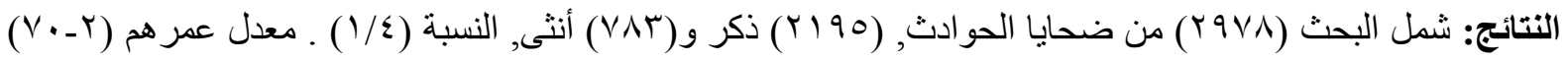

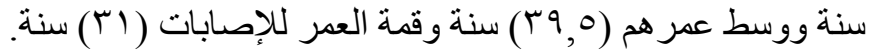

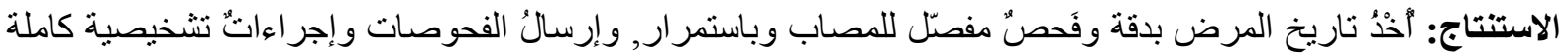

$$
\begin{aligned}
& \text { و إجر اء العملية الجر احية مبكر ا, في حالات إصابات البطن المغلقة, يؤدي الى تحسين الطرق العلاجية والاهتمام الجر احي. }
\end{aligned}
$$

I ncreased number of emergency admissions, unstable patients, incomplete histories, time-critical decisions, concurrent tasks, involvement of many disciplines and often junior personnel working after-hours in busy emergency departments create a perfect storm for medical errors. ${ }^{(1,2)}$ One of these avoidable errors is missed intra-abdominal injuries (MIAI), which could be defined as "unsuspected intra-abdominal injury requiring laparotomy in patients otherwise undergoing non operative management (NOM) ${ }^{(3)}$. It is clear that missed injuries adversely affect patients outcomes and damage physicians/institutional credibility (4) which could be avoided by "The timely treatment of the injury continues to rely on a high index of clinical suspicion and serial examinations by an experienced surgeon" ${ }^{(5)}$.The most common reason for injuries to be missed is altered level of consciousness due to head injury or alcohol. Other reasons include severity of injury and instability requiring immediate operation, lack of symptoms at admission, technical problems, and low index of suspicion by the examiner. ${ }^{(3,6)}$ Missed injuries can occur at any stage of the management of patients with major trauma, any delay in providing the treatment necessary may lead to increased morbidity and mortality. ${ }^{(7)}$ In many literatures the incidence of missed injuries is significant $(8.1 \%)(6,7)$. Understanding the etiology of missed injuries is essential in minimizing its occurrence. ${ }^{(6)}$. Among these injuries blunt abdominal trauma needs early and prompt identification and it can be challenging, and failure to detect these injuries initially can lead to preventable complications. (8).

Autopsies are useful in uncovering missed injuries or undiagnosed conditions that contribute to death after injury ${ }^{(9)}$, otherwise valuable information regarding possible missed injuries and potential improvements in management will be lost ${ }^{(10)}$.

Our aim is to find the frequency of the missed intra-abdominal injuries and their mortality, to raise the index of suspicion of potential missed injuries in order to avoid these preventable deaths, and improve the quality of the emergency medical services

\section{Methods}

A retrospective study including 2978 patients with abdominal injuries from the sum of 13201 traumatized patients in the 2006. Most of these patients were received directly after an accident from Al Sulaimaniyah city center or nearby areas which are served by AlSulaimaniyah Teaching Hospital/ a tertiary hospital in Iraqi Kurdistan Region, receiving annually over 20000 surgical emergencies. As recorded in the files; the initial examination was carried out by the trauma team in the Emergency Department (ED) according to standard protocols. Resuscitation was carried out according to Advanced Trauma Life Support principles. Patients were later reexamined as frequently as needed. Records were reviewed for demographics, injury characteristics, associated injuries, missed injuries, need and indications of reoperation, morbidity and mortality. Postmortem results of the 122 deceased patients were taken from Al Sulaimaniyah Forensic Institute; medical records of another 12 deaths were missing, who were excluded from the study. The study was approved by the Ethics Committee of the University of Al Sulaimaniyah-College of Medicine. All the data were analyzed by SPSS (statistical package for social science) version 16. Qui square analysis was done, $P$ value less than 0.05 was considered positive and statistically important. 


\section{Results}

The study included 2978 abdominal trauma victims; 2195 males and 783 females, with a male to female ratio of about 4:1.Thier age ranged from 2- 87 years, median age 39.5 and peak age of trauma was 31 years. Three quarters of the injuries were caused by blunt trauma, road traffic accidents being the commonest $(61.8 \%)$, and then falls (14.9\%). While in the penetrating injuries gunshot injuries (13.9\%) were the most frequent penetrating type. Mortality was $1.1 \%$ (134 patients, 12 exclude because of missing of their medical records). About two third of deaths had sustained head injury $(77.9 \%)$, only 28 deaths had abdominal injuries and many victims had multiple injuries (Table1).

From 2978 patients with abdominal injuries (Table 2), there were 28 deaths $(1.06 \%)$, and four missed injuries (0.134\%). Three missed injuries were intraoperative. One who had laparotomy for severely injured liver with severe haemoperitonium, and 49 hours later on reoperation, revealed shattered right kidney. The other two patients had undergone laparotomy for spleen avulsion and deep laceration in the spleen, while small intestine injuries were missed, revealed 4 days later during reoperation. The fourth one had multiple injuries by a heavy blunt object and was treated for the thoracic and orthopedic

Table (2): Details of the intra-abdominal injuries. injuries while abdominal injury in the form of duodenal damage was missed, and died on the $5^{\text {th }}$ postrauma day. Postmortem revealed missed posterior duodenal tear and periduodenal bilious debris and pus collection (Table 3).

We could notice that three quarters of the missed injuries (Table 4), were intestinal lacerations and occurred in the patients who sustained blunt abdominal injuries. Injuries were missed in two of the patients in the first operation, and the third diagnosed at autopsy.

Table (1): The frequencies of injuries in anatomical body regions.

\begin{tabular}{|l|c|c|}
\hline Injured Region & No. & $\%$ \\
\hline Head & 95 & 77.9 \\
\hline Multiple superficial wounds & 42 & 34.4 \\
\hline Lower limb fractures & 28 & 23 \\
\hline Chest & 21 & 17.2 \\
\hline Abdomen, pelvis & 28 & 23 \\
\hline Upper limb fractures & 17 & 13.9 \\
\hline Spine & 7 & 5.7 \\
\hline
\end{tabular}

* Some patients injured in more than one anatomical region.

\begin{tabular}{|l|c|c|c|}
\hline \multicolumn{1}{|c|}{ Injured organs } & No. and \% & Operated on & $\begin{array}{c}\text { Non-operative } \\
\text { management }\end{array}$ \\
\hline Abdominal wall & $804(26.99 \%)$ & 393 & 407 \\
\hline Small intestine & $435(14.60 \%)$ & 433 & 2 \\
\hline Pelvic \# with bladder and or urethra & $370(12.42 \%)$ & 370 & 0 \\
\hline Liver , spleen & $326(10.94 \%)$ & 326 & 0 \\
\hline Kidneys and ureter & $132(4.43 \%)$ & 18 & 114 \\
\hline Large intestine & $111(3.72 \%)$ & 111 & 0 \\
\hline Combined (Polytrauma) & $800(26.86 \%)$ & 369 & 431 \\
\hline Total & $2978(100 \%)$ & 1894 & 1084 \\
\hline
\end{tabular}


Table (3): Details of the missed intra-abdominal injuries in four patients.

\begin{tabular}{|l|c|c|c|}
\hline \multicolumn{1}{|c|}{ Stage of ATLS } & $\begin{array}{c}\text { Missed intra-abdominal } \\
\text { injury }\end{array}$ & $\begin{array}{c}\text { Survived } \\
\text { No. and \% }\end{array}$ & $\begin{array}{c}\text { Died } \\
\text { No. and \% }\end{array}$ \\
\hline Tertiary Assessment & Duodenal tear & 0 & 1 \\
\hline \multirow{2}{*}{ Intra-operative } & Renal injury & 0 & 1 \\
\cline { 2 - 4 } & Small intestine & 2 & 0 \\
\hline Total & 4 & 2 & 2 \\
\hline
\end{tabular}

Table (4): Details of the intestinal injuries s.

\begin{tabular}{|c|c|c|c|c|c|}
\hline \multirow{3}{*}{$\begin{array}{l}\text { Condition of the intestinal } \\
\text { injury } \\
\text { (Small and large })\end{array}$} & \multicolumn{3}{|c|}{ Type of the injury } & \multirow{3}{*}{ Missed injury } & \multirow{3}{*}{$P$ value } \\
\hline & \multicolumn{2}{|c|}{ Penetrating } & \multirow{2}{*}{ Blunt } & & \\
\hline & $\mathrm{HVM}^{*}$ & $S W^{\star \star *}$ & & & \\
\hline single & 46 & 37 & 463 & & 0.0317 \\
\hline $\begin{array}{l}\text { Combined with intra- } \\
\text { abdominal injuries }\end{array}$ & 39 & 10 & 90 & 2 (Blunt trauma) & \\
\hline $\begin{array}{l}\text { Combined with extra- } \\
\text { abdominal injuries }\end{array}$ & 2 & 1 & 32 & 1 (Blunt trauma) & \\
\hline
\end{tabular}

* HVM: High velocity missiles.

** SW; Stab wound.

$P$ value less than 0.05 considered significant.

\section{Discussion}

Missed injuries still occur at an unacceptably high rate in trauma patients ${ }^{(11)}$, it is mentioned in details in the literature and the incidence is $(8.1-22 \%)^{(6,7,11)}$. But incidence of missed intraabdominal injuries (3-18\%) is mentioned less in the literature ${ }^{(12)}$, claiming that it will not result in mortality, although it's associated with significant morbidity ${ }^{(5,13)}$. While others found $0.19 \%$ of necessary reoperation and $(0.29 \%)$ mortality in patients with missed injuries. In the results of the current work need for reoperation was $0.1 \%$ which is comparable to the literature (14) and mortality was (1.1\%) with ( $p$ value 0.0317).

Missed intestinal lacerations may be difficult to diagnose. There may be no initial or typical clinical presentation of the abdominal injuries especially in patients with multiple injuries or when there is change in the consciousness of the victim, even after examination with ultrasonography and CT scan of the abdomen and pelvis ${ }^{(5,11,12)}$, it is still not easy. Ultimately, the decision for exploratory laparotomy should be a clinical decision ${ }^{(5,13,15)}$ and high index of clinical suspicion helps in the recognition of these types of injuries ${ }^{(12)}$. The timely treatment of these injuries continues to rely on a high index of clinical suspicion and serial examinations by an experienced surgeon ${ }^{(5)}$, which may help in improving the quality of trauma care ${ }^{(11)}$.

Although in initial assessment, one still has to treat the greatest threat on life before complete diagnosis of all injuries, but alertness to evolving injuries must remain throughout the patient's stay in the hospital ${ }^{(7)}$ Acute physiological derangements can occur at any time after the original injury, with life threatening sequelae. ${ }^{(16)}$

The majority of treatment errors occur in the emergency department, the intensive care unit (ICU) and the operating room ${ }^{(11)}$. The results of this work revealed 4 missed intra-abdominal injuries (MIAI) (Table 3), one missed in the ED, ICU and there was no suspicion of the injury (duodenal lacerations) before death. Other three cases were missed in the ED, ICU and in the first operation (2 patients with small intestinal lacerations and one with shuttered right kidney).

The presence of associated intra-abdominal injuries significantly affected the presentation and time of diagnosis of patients with small 
bowel injuries(SBI) ${ }^{(12)}$ and any delay in the surgical treatment in trauma victims over 90 min increases mortality of $1 \%$ every 3 minutes ${ }^{(17,18)}$. Patients inflicted with more severe associated injuries were less likely to survive the trauma ${ }^{(12)}$.

\section{Conclusion}

A careful history taking, precise and repeated clinical examinations, complete diagnostic procedure, complete surgical explorations, and timing early reoperation are necessary for patients with blunt abdominal injuries, which are cornerstones in improving the quality of trauma care.

\section{Acknowledgements}

We would like to thank all the doctors on duty in Al Sulaimaniyah Casualty Hospital; paramedical workers for their technical support, and we also thanks Dr. Fatah Hawramani for his statistical analysis of the results.

\section{References}

1. Huynh $\mathrm{T}$, Blackburn $\mathrm{H}, \mathrm{Mc}$ Middleton $\mathrm{D}$, Moran R, Thomason H, Jacobs G. An Initiative by Midlevel Providers to Conduct Tertiary Surveys at a Level I Trauma Center 2010; 68(5):1052-1058.

2. Russell L, Gregory J, Lisa K, Hugh M, Ronald V. Patterns of Errors Contributing to Trauma Mortality: Lessons Learned From 2594 Deaths. Annals of Surgery 2006; 244(3):371-380.

3. Enderson L, Reath B, et al. The Tertiary Trauma Survey: A Prospective Study of Missed Injury, Journal of Trauma-Injury Infection \& Critical Care 1990; 30(6): 666670.

4. Biffl L, Harrington T, Cioffi G. Implementation of a Tertiary Trauma Survey Decreases Missed Injuries, Journal of Trauma-Injury Infection \& Critical Care 2003;54(1):38-44.

5. Malhotra K, Fabian C, Katsis B, Gavant L, Croce A. Blunt Bowel and Mesenteric Injuries: The Role of Screening Computed Tomography 1990; 30(1):1-7.

6. Gordon B, Donna I. Missed Injuries. Journal of Trauma-Injury Infection \& Critical Care 2000; 49(4):600-605.
7. Houshian S, Larsen S, Holm C. Missed Injuries in a Level I Trauma Center, Journal of Trauma-Injury Infection \& Critical Care 2002; 52(4):715-719.

8. Stephen $T$, James $C$, Donald $W$. Pediatric Blunt Abdominal Trauma, Pediatr Clin N Am 53 2006; 243- 256.

9. Osvaldo C, Stefania C, Alessio P, Sergio V. Preventable trauma deaths: from panel review to population based-studies. World Journal of Emergency Surgery 2006;1:12.

10. Hilty MP, Behrendt I, Benneker LM, Martinolli L, Stoupis C, Buggy DJ, Zimmermann $\mathrm{H}$, Exadaktyl, Diminishing Role. World J Emerg Surg 2008; 3:11-15.

11. Roman P, Hans-Christoph P, Missed injuries in trauma patients: A literature review, Patient Safety in Surgery 2008; 2:20.

12. Fraga G, Bergo de Souza, de Almeida N, et al. Blunt abdominal trauma with small bowel injury: are isolated lesions riskier than associated lesions?, Acta Cirúrgica Brasileira 2008; 23 (2): 192-197.

13. Soundappan S, Holland A, Cass DT. Role of an Extended Tertiary Survey in Detecting Missed Injuries in Children, Journal of Trauma-Injury Infection \& Critical Care 2004; 57(1):114-118.

14. Stephan Phillip J, McCarley MC, O'Keefe GE, Minei JP. 23-Hour Observation Solely for Identification of Missed Injuries after Trauma: Is It Justified? Journal of TraumaInjury Infection \& Critical Care 2002; 53(5):895-900.

15. Chew K, Amin N. Handlebar Herniation: A Case of Near Missed Abdominal Injury, Med J Malaysia 2009; 64 (2):213-5.

16. Runciman $W$, Griggs $M$, Morris $W$, Osborne A, Paix D. Trauma: development of a sub-algorithm, W M Griggs, R W Morris, W B Qual Saf Health Care 2005; 14( 3):499-500.

17. Hilbert $P$, Hoeller J, Wawro W. Emergency Patients: A Multi-slice CT-oriented Care Algorithm. Injury 2007;38:552-558.

18. Hilbert $P$, Hoeller J, Wawro $W$, et al. Emergency room management of multiple injured patients. A multislice computed tomography orientated treatment algorithm, Anasthesiol Intensivmed 2005;40(12):720-5. 